\title{
A comunicação do tempo em Proust
}

\author{
Regina Rossetti ${ }^{1}$ \\ Universidade Municipal de São Caetano do Sul \\ epitofilos@uol.com.br
}

\begin{abstract}
Resumo: Comunicação, Filosofia e Literatura se encontram no Tempo. Partindo do problema filosófico proposto por Bergson sobre a intuição e sua comunicação, mostramos como Proust, em seu romance Em busca do tempo perdido, comunicou sua visão do tempo por meio de imagens e metáforas. A obra de arte pode expressar a passagem do tempo.
\end{abstract}

Palavras-chave: Comunicação; Literatura; Fìlosofia.

Abstract: Communication, Philosophy and Literature find in the Time. Leaving of the philosophical problem considered by Bergson on the intuition and its communication, we show as Proust, in his romance À la recherche du temps perdu, communicated his vision of the time by means of images and metaphors. The arts can express the passage of the time.

Words keys: Communication; Literature; Philosophy.

Résumé: Communication, Philosophie et Littérature si trouvent dans le temps. Partir du problème philosophique considéré par Bergson sur l'intuition et sa communication, nous montrons comme Proust, dans son roman À la recherche du temps perdu, a communiqué sa vision du temps au moyen d'images et métaphores. L'oeuvre d'art peut exprimer le passage du temps.

Clefs de mots: Communication ; Littérature ; Philosophie.

Resumen: Comunicación, Filosofía y Literatura si hallazgo en el tiempo. El irse del problema filosófico considerado por Bergson em intuición y su comunicación, demostramos como Proust, en su romance À la recherche du temps perdu, comunicó su visión del tiempo por medio de imágenes y metáforas. La obra de arte puede expresar el tiempo.

Palabras claves: Comunicación; Literatura; Fìlosofia.

\footnotetext{
${ }^{1}$ Pós-doutora pelo Departamento de Filosofia da Faculdade de Filosofia, Letras e Ciências Humanas da Universidade de São Paulo - USP. Autora de "Movimento e Totalidade em Bergson: a essência imanente da realidade movente" (São Paulo: Edusp, 2004). Professora na Universidade Municipal de São Caetano do Sul - IMES.
} 


\section{Introdução}

O tempo é um dos temas de maior interesse para a comunicação, visto que no tempo ela fundamenta muitos de seus processos. Tema complexo, pois o tempo não é um só e submetido ao devir muda em suas configurações. $\mathrm{Na}$ chamada pós-modernidade o tempo é outro, não é mais compreendido apenas como um tempo linear, uma sucessão causal de acontecimentos justapostos na linearidade do passado, presente e futuro. O tempo, na cultura midiática, é virtual, complexo, às vezes com sobreposição de seus momentos, dinâmico e plural.

Para pensar esse novo tempo em um contexto comunicacional cujos suportes tecnológicos modificam nossa noção de tempo e espaço, precisamos antes compreender o próprio tempo. Neste sentido, talvez o filósofo francês Henri Bergson, cujo tema principal de sua obra foi o tempo, possa ajudar a esclarecer o problema, mostrando como o tempo real não é o tempo cronológico marcado pelo relógio, mas um tempo criador que muda incessantemente a própria realidade.

Compreendido o tempo, em sua dimensão inovadora, surge então, a grande questão que interessa mais de perto aos estudos comunicacionais: como dar expressão a esse tempo que traz em si a própria novidade? Como narrar o tempo que muda? Como comunicar nossa visão de um tempo fugaz que escapa às várias tentativas de expressão? Neste sentido, talvez o romancista Proust possa nos dar indícios de uma proposta superação do problema da expressão do tempo. E assim Filosofia e Literatura possam contribuir para que a Comunicação encontre elementos para sua reflexão acerca do tempo e de como expressá-lo.

Bergson, ao intuir a essência de toda existência, teve a visão de que o tempo é o estofo da realidade. Ao tentar dar expressão a essa intuição percebeu os limites da linguagem conceitual quando se trata de comunicar o tempo intuído; isto porque o tempo é fugaz e a expressão fixa em palavras o 
movimento daquilo que é significado. Proust, por sua vez, foi em busca do tempo perdido, e para narrar sua visão do tempo como essência de todas as coisas, escreveu um romance monumental. Não teria Proust dado expressão a sua intuição de tempo por meio da obra de arte e assim conseguiu comunicar o tempo in-comunicado de Bergson?

Pensamos que sim. Para comunicar a visão da fluidez do tempo é necessário um modo de expressão tão fugidio quanto o próprio tempo. Nesse sentido, Bergson apresenta a metáfora como capaz de sugerir essa visão ao interlocutor, e propõe o uso de imagens e metáforas para expressar e tornar possível a comunicação da intuição da essência temporal da realidade. Do mesmo modo, as metáforas proustianas são celebres e seu uso exaustivo permitiu a Proust comunicar aos seus pacientes leitores sua própria intuição do tempo.

Este artigo trata da comunicação da intuição do tempo aproximando o esforço literário de Proust do pensamento do filósofo Bergson. Parte do problema da comunicação da intuição do tempo proposto por Bergson e mostra como a intuição do tempo pôde ser comunicada por meio de imagens e metáforas no romance proustiano.

\section{A inovação do pensamento bergsoniano no campo das artes}

A atmosfera espiritual do começo do século XX na França continha brisas do pensamento do filósofo Bergson. Segundo Floris Delattre, "sua influência fecunda se manifesta, sobretudo, em todo o domínio espiritual francês, da sociologia à moral e à religião, à pintura e à música” ${ }^{2}$ O pensamento bergsoniano era inovador e rompia com a tradição. Novas noções como intuição, duração, tempo criador, qualidade, continuidade, fluxo movente da consciência e da realidade, élan vital, entusiasmaram o grande público que aderiu rapidamente a elas. Num contexto em que as ciências

\footnotetext{
${ }^{2}$ DELATTRE, Floris. "Bergson e Proust: Accords et dissonances". In: Les Études Bergsoniennes I. Paris: P.U.F., 1948, p. 14.
} 
positivas começavam a perder sua força de convencimento e a inteligência mostrava seus limites, iniciou-se um movimento de busca da subjetividade, da interioridade, do inconsciente, das forças vitais para além da racionalidade, enfim, um movimento voltado para as profundezas misteriosas do espírito. Novos anseios e necessidades que o pensamento de Bergson, de certa maneira, aos olhos da sociedade, correspondeu.

Particularmente, houve ressonâncias do pensamento de Bergson no campo das artes, ávida de novos horizontes intelectuais que lhe servissem de inspiração. As novas idéias bergsonianas como a crítica da inteligência limitada à ação e a superioridade da intuição voltada para o espírito influenciaram decisivamente o movimento do Simbolismo3. Primeiramente na poesia, a metafísica de Bergson serviu de garantia intelectual aos poetas simbolistas que buscavam uma comunicação direta do sensível. Na música, Debussy, por exemplo, visando exprimir o inexprimível e traduzir musicalmente sua busca introspectiva dos mistérios da consciência seguindo o andamento da duração real, tinha objetivos semelhantes aos da metafísica bergsoniana. Na literatura, foram vários os escritores que encontraram em Bergson uma nova concepção filosófica que ia ao encontro de suas necessidades de renovação da literatura romanesca. Não é à toa que a História da Literatura da Enciclopédia da Pléiade inicia o capítulo sobre a Literatura do Século XX falando exatamente sobre Henri Bergson. Os livros de Bergson segundo a Enciclopédia, "refletem assim a luz do sol poente simbolista. Entre bergsonismo e literatura, as correspondências são muitas"4. Delattre, por sua vez, cita vários escritores romancistas deste período que respiravam " o ar do bergsonismo", rejeitando as velhas fórmulas deterministas e naturalistas de descrever o mundo e renunciando à experiência exterior e intelectualmente

\footnotetext{
3 “D'ailleurs, la philosophie de Bergson se rattache sans aucun doute à un autre mouvement littéraire: c'est à savoir: le simbolisme. Or il est incontestable que Proust ait subi au début de sa carrière l'influence de ce mouvement", SOUZA, p. 4. ${ }^{4}$ QUENEAU, Raymond, (org.). "Histoire des Littératures III". In: Encyclopédie de la Pléiade. Paris: Ed. Gallimard, 1958, p. 1252.
} 
objetiva como modelo de construção de seus romances. O olhar do escritor buscava agora a introspecção; o alvo é o indivíduo e sua interioridade. Por meio da crítica ao puro intelectualismo e aos imperativos sociais, os escritores buscavam dar ao leitor uma sensação intensa do mistério da vida e do espírito e, assim, restituir ao indivíduo a apreensão direta de sua própria realidade integral5. Assim, podemos afirmar que houve um aproveitamento marcante dos pressupostos tanto metafísicos quanto filosóficos do pensamento bergsoniano pelos novos movimentos artísticos, notadamente o literário, do começo do século.

Neste contexto filosófico-artístico, o romance de Marcel Proust, “ em busca do tempo perdido" é privilegiado. Segundo Delattre, ele reúne em si todos os componentes do novo movimento literário que busca o que há de mais profundo na interioridade do espírito, rejeitando as velhas descrições exteriores e intelectualistas do mundo. "Sua obra inteira participa do impulso dado pela filosofia bergsoniana, se ela mesma não procede dela diretamente" ${ }^{\text {"6. }}$.

Nesse sentido, podemos considerar que existe uma correspondência possível entre a Proust e Bergson, "há um tom bergsoniano do mundo proustiano, como de todo romance do tempo rememorado e do monologo interior" ". Bergson e Proust foram contemporâneos e respiraram uma atmosfera intelectual comum. Brincourt vai mais longe e afirma que: "a obra de Proust pode, entretanto, ser considerada como um dos prolongamentos possíveis da filosofia bergsoniana, e sobre o plano da psicologia

\footnotetext{
5 "C'est la recherche de l'individu encore, de la complexité changeante et imprévisible, toujours unique, de êtres, ce sont les thèmes proprement bergsoniens donc touchant la personalité qui retiennent l'attention particulière de jeunes romanciers" DELATTRE, p. 24.

${ }^{6}$ DELATTRE, p. 25.

${ }^{7}$ QUENEAU, p.1252.
} 
afetiva, e sobre o da estética"8. Segundo Brincourt, são como etapas distintas e importantes no curso de um mesmo movimento espiritual ${ }^{9}$.

Além de temas comuns, o tempo, a interioridade e a memória, tanto Bergson quanto Proust têm um mesmo ponto de partida: a vida interior. Bergson inicia seus estudos debruçando-se sobre a psicologia para melhor compreender a realidade temporal da vida psíquica e Proust vai a busca das lembranças guardadas na memória e faz de sua própria vida interior o motivo para escrever acerca do tempo. Por isso é proveitoso resgatarmos a concepção de Bergson e seus inovadores estudos acerca da vida interior que partem de uma rigorosa crítica aos pressupostos filosóficos da psicologia de sua época, presentes em seu primeiro livro, Ensaio sobre os dados da consciência. Estes pressupostos são criticados por Bergson, com um olhar agudo e perspicaz, que vai a busca da real essência dos estados psicológicos, rompendo com os velhos paradigmas deterministas do século XIX. Este Ensaio foi provavelmente objeto de leitura e de reflexão para Proust. Isto tudo nos permitirá compreender a real possibilidade de aproximações entre a filosofia de Bergson e a literatura de Proust quanto à comunicação da intuição do tempo. Posicionando Bergson como um apoio filosófico que nos permitirá compreender a obra de arte proustiana a partir de uma nova perspectiva de reflexão.

\section{O ponto de partida bergsoniano: o problema da comunicação da intuição}

Essa possível correspondência justifica este estudo acerca das relações entre a literatura de Proust e a filosofia de Bergson. Mas não é a única justificativa. Bergson nos deixou um problema, no qual nos apoiamos para darmos impulso a este estudo: a comunicação da intuição do movimento

\footnotetext{
${ }^{8}$ BRINCOURT, p. 39.

9 "Nous pouvons donc admettre que Bergson, Proust e Malraux ont recuilli les idées maîtresses de leur temps sur l'esthétique. Em eux, ces idées se sont exaltées singulièrement, elles ont pris une force nouvelle, se sont imposées aux esprits. Ainsi Bergson, Proust et Malraux, par leurs points de vue sur l'art, semblent-ils avoir determine trios étapes importantes et distinctes dans le cours d'unmême mouvement spirituel”, BRINCOURT, p. 35 .
} 
essencial da realidade. Então, é justificável que, partindo da própria filosofia bergsoniana, extrapolando seus limites rumo a uma direção por ela mesma indicada, busquemos, fora da filosofia, tentativas de superação de tal problemática no intuito de aprofundar nosso conhecimento do pensamento bergsoniano e pesquisar acerca de sua amplitude.

Nosso ponto de partida é o problema da comunicação da intuição da duração - duração entendida como o movimento essencial da realidade movente, ou dito de outro modo, duração entendida como o tempo criador de novas formas. Problema que remete ao conhecimento que por sua vez fundase numa ontologia. Para Bergson a realidade é ontologicamente movente e sua essência é a duração. Duração é a essencial mudança incessante e contínua da realidade que, por sua vez, também é movente e indivisível. Duração é tempo, contudo, não é o tempo do senso comum ou da ciência, mas é um tempo criador da própria realidade; tempo que nos habita e nos constituí, tornandonos criadores também.

Contextualizando a problemática, vemos que a metafísica tradicional sempre pretendeu conhecer a realidade tal como é em sua essência e para comunicar esse conhecimento, em um discurso filosófico, utilizou-se de conceitos. Nesse momento é que surge o problema aqui tratado. A linguagem conceitual mostra-se incapaz de expressar a essência de uma realidade movente. Isto porque o conceito, proveniente da cristalização da significação simbólica, paralisa o movimento das coisas para poder expressá-la, conseqüentemente, o conceito, ao tentar expressar a realidade movente, retira dela o essencial, isto é, seu movimento. Logo, a linguagem conceitual é incapaz de dizer a essência da realidade e, assim, ao invés de aliada da metafísica é empecilho.

Para a nova metafísica bergsoniana, a única forma de conhecimento capaz de nos dar a essência da realidade movente é a intuição, precisamente porque segue seus contornos móveis, aderindo precisamente a eles. 
Entretanto, essa intuição em sua pureza não pode ser expressa por meio de símbolos, conceitos ou palavras, pois todas essas representações simbólicas remetem a uma forma de expressão exterior e fixa, e a intuição, por sua vez, é sempre interior e móvel. Essa impossibilidade de expressar adequadamente aquilo que é captado pela intuição, por meio de conceitos, faz surgir um dos problemas mais instigantes da filosofia intuitiva, o problema da comunicação da intuição. Resumido da seguinte forma: se a intuição é conhecimento, então deve ser expressa em linguagem, todavia, a linguagem somente dispõe de símbolos e, particularmente, de conceitos para se expressar; os conceitos paralisam o fluxo movente da realidade e, assim, a deformam ao tentar definila; logo, resta a questão: como expressar filosoficamente a intuição do movimento incessante da realidade, sem paralisá-lo? A intuição, em sua pureza original, pode ser comunicada ao outro? E mais ainda, estaria a linguagem fadada a não dar conta de dizer o ser?

Na própria origem intelectual dos conceitos pode estar a resposta para o impasse, o que faz com que a superação não seja completa isto porque somente a inteligência pode comunicar a intuição. “A intuição, aliás, somente será comunicada por meio da inteligência. Ela é mais que idéia, ela deverá, todavia, para lograr transmitir-se, cavalgar algumas idéias. Ao menos, ela dirigirá de preferência às idéias mais concretas, rodeadas ainda por uma franja de imagens. Comparações e metáforas sugerirão aqui o que não poderemos chegar a exprimir”. ${ }^{10}$ Posto o problema, Bergson aponta para uma possível saída sugerindo outro caminho: a utilização de imagens e metáforas para exprimir a intuição da realidade movente. Isto porque a metáfora não se fixa em um significado único, mas transmigra-se por várias significações, acompanhando as oscilações do real. Não é à toa que Bergson procura escrever de forma clara, fluida e dinâmica, como um rio fluente e límpido numa trajetória segura para quem nela adentra e, também, procura utilizar-se

\footnotetext{
${ }^{10}$ BERGSON, H. Textos escolhidos. Trad. Franklin Leopoldo e Silva. São Paulo: Abril Cultural, 1984. (Os Pensadores), p.122.
} 
de muitas imagens, metáforas e analogias que muito mais sugerem que definem, pois a realidade que ele pretende comunicar é movente e fugaz, e presta-se muito mais à sugestão do que à definição.

\section{O novo romance proustiano e o tempo comunicado}

Nesse sentido a arte aparece como paradigma ${ }^{11}$ para a filosofia, porque, naturalmente, utiliza-se de imagens e expressões metafóricas para expressarse e comunicar seu significado ${ }^{12}$. Claro que devemos estar atentos ao limites que separam a arte da filosofia. Proust, por exemplo, é um artista, que toca a essência das coisas, a região mais profunda e verdadeira do real, portanto, realiza uma tarefa que também é a do filósofo; porém, ele não é um filósofo, não parece preocupado com o rigor e a coerência de sua obra, como Bergson, por exemplo. O artista, por sua própria natureza, está mais preocupado em tornar visível sua contemplação, em sugerir mais do que demonstrar logicamente uma tese, entretanto, seu modo de exprimir-se pode ser emprestado a uma filosofia intuitiva que deseja tornar visível a intuição da essência movente da realidade.

Ao lermos o romance de Proust podemos verificar que ele consegue, não somente pelo assunto principal de sua obra - o tempo -, mas também por meio de seu estilo único, dar conta de comunicar a fluidez da realidade em constante mudança. Proust possui uma nova forma de expressão, própria e original: um turbilhão de impressões descritas até a exaustão; um estilo que busca trazer para a literatura a nova forma de expressão típica da pintura impressionista: os contrastes de luz, a ausência de contornos precisos, a fusão de imagens sobrepostas, o movimento e a fluidez eternizados em um único momento. Outra característica marcante do estilo proustiano é a profusão de

\footnotetext{
11“ não apenas existe uma extraordinária afinidade entre arte e Filosofia como também a arte se põe como paradigma do discurso filosófico", LEOPOLDO E SILVA, F. Bergson e Proust: o impressionismo como obstáculo e transparência, p. 153.

12 "Bergson est donc tout naturellement amené à trouver une preuve de sa théorie dans les donnés de l'art”, BRINCOURT, p. 43.
} 
metáforas que brotam o tempo todo do texto, buscando sugerir por imagens aquilo que ele acabou de fazer notar de uma forma mais descritiva; nesse momento nos deparamos com o constante "como se", numa linguagem conotativa e cheia de significados. Uma terceira característica de seu estilo é o uso constante do passado imperfeito nas frases; um tempo verbal que prolonga o passado no presente, dando a idéia de um tempo que continua, nem completamente passado, nem completamente presente.

O leitor que mergulhar na correnteza tempestuosa do estilo proustiano, se não se atordoar porque "o verdadeiro leitor de Proust é constantemente sacudido por pequenos sobressaltos"13, pode sentir o movimento do fluxo da narração, escoando livre e imprevisível. O fluxo de milhares de impressões fugidias, narradas no romance, que buscam mostrar o caráter único, novo e continuamente infinito da vida. Esforço narrativo que, segundo Delattre, Bergson considera fundamental quando se trata de comunicar a duração e a vida. "Pois que a vida, tanto para o romancista como para o filósofo, é um acontecimento universal, no qual nada é inerte, imóvel; sendo a imobilidade a definição da morte, seu romance será aquele da duração vivente, a pintura de uma experiência interior sentida e exprimida na totalidade sucessiva ${ }^{14}$.

Embora imbuído do sentido puro da duração concreta, móvel e criadora, Proust não adota uniformemente esta noção em sua obra. Muitas vezes, aparece a noção de um tempo espacializado, atravessado pelas construções da inteligência, que Proust apesar de criticar, por vezes, não consegue dela escapar. Mesmo assim, são muitas as características de seu estilo que permitem a Proust expressar a temporalidade de uma realidade em constante movimento. O que nos leva a perguntar se para o problema bergsoniano da comunicação da intuição da realidade movente, não seria

\footnotetext{
${ }^{13}$ BENJAMIN, p. 43.

${ }^{14}$ DELATTRE, p. 49.
} 
Proust uma tentativa inovadora e bem sucedida de expressão literária de uma realidade movente e temporal em plena duração? ${ }^{15}$.

Proust intentou narrar o tempo em $\grave{A}$ la recherche du temps perdu. Tarefa nada fácil, porque se é obrigado a utilizar palavras para comunicar, palavras que fixam o sentido do que é significado, no caso fixam o fluxo essencial do tempo, e fixar o fluxo do tempo é retirar dele o que tem de mais essencial. Thomas Mann, num trecho de "A Montanha Mágica”, pergunta se “Pode-se narrar o tempo, o próprio tempo, o tempo como tal e em si?”. Tarefa cheia de obstáculos porque o tempo é algo que decorre, escoa, segue o seu curso e que, portanto, sempre foge; e se foge como retê-lo para narrá-lo? É exatamente esta a dificuldade central de qualquer tentativa de narrar o tempo, dificuldade que Proust teve que enfrentar e superar.

\section{As metáforas proustianas}

Descoberta a matéria de sua obra, o tempo, como comunicá-lo? ${ }^{16}$ Antes é necessário superar um obstáculo intrínseco à própria narrativa do tempo: sua fugacidade. Em Proust a contemplação da essência das coisas, por ser retirada do tempo, é sempre fugidia. O tempo é fugaz por isso escapa às nossas tentativas segurálo numa imagem fixa. Então, surge o problema: como reter a fugaz visão da essência, ou seja, como fixar a contemplação sempre fugidia que se manifesta por meio de um instante de tempo puro? E a resposta vem inequívoca: a intuição da essência das coisas somente pode ser retida pela obra de arte. Não poderia ser por meio da lógica ou da inteligência com suas verdades diretas e claras, mas superficiais em relação à profundidade da vida. Nesta busca do eterno, faz-se necessário tentar interpretar as sensações como signos, tentando transformar o sentimento em seu equivalente

\footnotetext{
15 “C'est ainsi que Proust s'est engage, sans en avoir nettement conscience, dans des voies ouvertes par Bergson, et qu'il est allé plus lion que lui, pénétrnt dans des territories jusque là inexplorés", BRINCOURT, p. 40.

16 "Por isso, essa contemplação das essências das coisas, estava agora bem resolvido a retê-la, a fixa-la, mas como?”, T.R., p. 156.
} 
espiritual por meio da realização de uma obra de arte, único meio de fixar a essência fugidia do ser e comunicar a realidade temporal das coisas.

Comunicar a intuição do tempo exige uma forma de expressão tão fugidia e móvel quanto o próprio tempo, forma de expressão que Proust encontrou na metáfora. Nesta busca de tentar apreender a essência fugidia da realidade é que encontramos o papel fundamental da metáfora em Proust, "por meio de uma qualidade comum a duas sensações, lhe extrair a essência, confundindo-as, para as subtrair às contingências do tempo, ligando-as pelo laço indescritível de uma aliança de palavras."17 Segundo Genette: "a metáfora é a expressão privilegiada de uma visão profunda: aquela que vai além das aparências para ter acesso à essência das coisas"18. A metáfora é um instrumento imprescindível da reconstituição da visão das essências. A metáfora seria o equivalente estilístico da experiência da memória involuntária, que pela aproximação de duas sensações separadas no tempo força a manifestação de uma essência comum; da mesma forma que a metáfora pela analogia de duas coisas diferentes consegue extrair uma essência comum, com a vantagem de contar com a perenidade da obra de arte, coisa que a memória não consegue por ter uma visão sempre fugitiva da eternidade. Assim, a metáfora consegue dar conta de sugerir aquilo que por sua própria natureza não se presta às descrições imobilizantes e superficiais do discurso denotativo. Para Proust a tarefa do escritor é a mesma do tradutor: "eu veria que, para exprimir tais sensações, para escrever esse livro essencial, o único verdadeiro, um grande escritor não precisa, no sentido corrente da palavra, inventá-lo, pois já existe em cada um de nós, e sim traduzi-lo. O dever e a tarefa do escritor são as do tradutor"19. Traduzir em palavras as impressões deixadas pelo tempo na alma do escritor, e assim comunicá-las ao leitor. Não com palavras em seus sentidos literais e

\footnotetext{
${ }^{17}$ T.R., p. 167.

${ }^{18}$ GENETTE, p. 42.

${ }^{19}$ T.R., p. 168.
} 
descritivos, mas por metáforas, analogias, comparações e imagens. Proust utilizará constantemente uma multiplicidade de imagens para sugerir uma impressão, o que o aproxima muito da proposta bergsoniana do uso da imagem para comunicar uma intuição. ${ }^{20}$

Há em Proust uma busca do eterno, do universal, do geral, que ele torna sentida em seu estilo. A busca da essência das coisas está refletida no estilo proustiano que Genette chama de estilo-substância "capaz de restituir somente pela força de seu alto grau de fusão a unidade material das coisas”21. Proust, em uma carta a Lucien Daudet, faz referência a essa idéia de estilosubstância vislumbrada em seu romance: "em que se realizou o milagre supremo, a transubstanciação das qualidades irracionais da matéria e da vida em palavras humanas”. Proust ao descrever a substância cria um estilo próprio que por isso pode parecer complexo, complicado, porque complexas e implicadas umas nas outras são as tramas da vida, as personalidades, as impressões que o tempo deixa em nosso espírito. Segundo o que nos diz Spitzer, no romance de Proust podemos encontrar por trás do efêmero, o eterno e por trás do particular, o universal22. Expressar um tempo absoluto, uma essência universal é a tarefa que Proust procura realizar por meio de sua obra literária, fazendo uso de um estilo que possa deixar passar o tempo que passa. Segundo Deleuze, o artista consegue revelar a essência encarnada na matéria quando seu estilo é capaz de espiritualizar a matéria (os sons, a cor, as palavras). "O estilo, para espiritualizar a matéria e torná-la adequada à essência, reproduz a instável oposição, a complicação original, a luta e a troca

\footnotetext{
20 "Constitué par une intention vide, le signe ne révèle pas l'objet. L'image, au contraire, grâce à sés prestiges, fait appareître présent l'objet absent. Proust utilisera très souvent une multiplicité d'images pour suggérer une impresión. Son esthétique d'images s'accorde, sur ce point encore, avec celle de Bergson”. BRINCOURT, p. 56.

${ }^{21}$ GENETTE, p. 44.

22 "Comme les symboles, cette exagération dans les images trouve son explication: par-delà les petits faits, il faut cherche les grandes choses, le contigent est dominé par l'éternel". SPITZER, p. 456.
} 
dos elementos primordiais que constituem a própria essência”23. Proust procura dar forma a um esquema que o persegue: o desejo de unir, numa expressão nova, a sensação à emoção que ela suscita. O estilo da Recherche se afirma na sua profunda originalidade pelo caractere especial de suas imagens e de seus ritmos. ${ }^{24}$ Sua frase tem um ritmo único. As engenhosas correspondências entre os membros da frase, a variedade de finais, sua sinuosa lentidão habitual que dá lugar de tempos em tempos a seus movimentos bruscos e rápidos, fazem um estilo que pertence somente a Proust. Segundo Spitzer, as frases de Proust não são cinematográficas, mas calendoscópicas, nesse sentido aproximam-se da proposta bergsoniana que alerta para a ilusão cinematográfica das imagens 25 .

Para Proust o estilo é basicamente metáfora, única capaz de dar conta dessa instável oposição, dessa essência na qual encontraremos o tempo em sua origem. Para Deleuze o mundo das essências é sempre um começo do mundo em geral e do nascimento do tempo. Isto pode ser visto quando Proust se refere à essência e à obra de arte como uma instável oposição: "essa perpétua recriação dos elementos primordiais da natureza"26. $\mathrm{O}$ artista tem a revelação do tempo original como enrolado, complicado com todas as suas dimensões imbricadas ainda na própria essência. Por meio do sujeito-artista é a arte que nos faz redescobrir o tempo em seu estado original, ainda enrolado na essência, tempo que é idêntico à eternidade, ao extratemporal, o que leva Deleuze afirmar: "que só a obra de arte nos faz redescobrir o tempo: a obra de arte é o" único meio de redescobrir o tempo perdido"27. O estilo das frases e do andamento da narrativa de Proust espelha esta complicação, esta constante

\footnotetext{
${ }^{23}$ DELEUZE, Proust e os signos, p. 48.

${ }^{24}$ BRINCOURT, p. 168.

25 "Lorsque Proust parvient au mouvement continu de Bergson, ce n'est pas par ces accumulations d'images diverses, si nombruses soient-elles: elles sont décrites trop minutieusement pour que le lecteur ne s'arrête pas sur chacune, l'isolant ainsi necessairment de l'image voisine”, SPITZER, P.420.

${ }_{26}$ Proust citado por DELEUZE, Proust e os signos, p.45.

${ }^{27}$ DELEUZE, Proust e os signos, p. 46.
} 
implicação das essências umas nas outras. As anacronias, frases imbricadas, emaranhadas, longas, cheias de idas e vindas, seus personagens contraditórios, revelando facetas até mesmo opostas, são formas de tentar expressar este tempo e esta essência original de todas as coisas.

Brincourt ${ }^{28}$ afirma que o estilo de Proust traduz o esforço que Bergson considerava indispensável para comunicar os segredos da duração da consciência, estilo que levava a uma impressão quase física do tempo ${ }^{29}$. Depois de captar e perceber a realidade resta ainda comunicá-la. Embora essa comunicação não seja espontânea e exija muito esforço de expressão por parte do artista.30 Assim, podemos dizer que a duração bergsoniana encontra-se comunicada no romance de Proust, seja de forma mais visível e ilustrativa, por meio da duração de seus personagens, seja de forma mais essencial, pelo assunto principal de sua obra: o tempo. Segundo Brincourt, para Bergson a visão do artista é uma percepção intuitiva da realidade das coisas, destacada das necessidades da vida prática, da mesma maneira que para Proust uma impressão ressentida e laboriosamente explicitada para reencontrar a realidade do eu deve ser a substância mesma do fato artístico. Tanto para um como para o outro, trata-se de um grande esforço intelectual que o artista chega a se exprimir, a se tornar comunicável. ${ }^{1}$

\section{Considerações finais}

Podemos vislumbrar em Proust a comunicação, por meio de suas metáforas e de seu estilo vertiginoso, da intuição da essência fugidia das coisas

\footnotetext{
28 "Bergson et Proust ont montré que le style est toujours rythme et parfois métaphore. Ainsi, nous avons pu nous render compte qu'en literature une vie des forme s'inscrit, s'organise dans la matière verbale". BRINCOURT, p. 57.

29 "l'impression quasiment physique de la durée, cette continuité essentielle que Bergson avait imposée à sa pensée”DELATTRE, p. 45.

30 "Mais, s'il l'aperçoit, il doit encore la communiquer. Pour rendre communicable à tous, par ce langage, cette impression personnele, l'artiste doit faire - em peline conscience - um effort considérable”. BRINCOURT, p. 46.

${ }^{31}$ BRINCOURT, p. 51.
} 
em constante renovação. Comunicação que Bergson considerou impossível por meio da linguagem conceitual que solidifica no conceito a fluidez da realidade movente. Fluidez que poderia ser sugerida por metáforas e por imagens, que por serem modos de expressão móveis em seu significado, poderiam acompanhar o devir contínuo da realidade e, assim, comunicar a intuição que se pode ter desse devir. E somente um "romancista audacioso" poderia fazê-lo.

Concluindo, podemos dizer que em nossa busca de um paradigma artístico que, ao menos, amenize o problema da comunicação da intuição da realidade essencialmente movente, Proust pode ser tido como uma tentativa bem sucedida de expressão da realidade temporal em sua duração. Proust comunicou por meio de seu estilo e de suas inumeráveis metáforas o tempo criador que Bergson considerava impossível de ser comunicado por meio de conceitos.

\section{Bibliografia}

BENJAMIN, W. Obras escolhidas I. Trad. Rouanet. São Paulo; Brasiliense, 1987.

BERGSON, H. Textos escolhidos. Trad. Franklin Leopoldo e Silva. São Paulo: Abril Cultural, 1984. (Os Pensadores)

BRINCOURT, A. et J. Les Oeuvres et les Lumières. Paris: La Table Rond, 1955.

DELATTRE, F. Bergson et Proust: Accords et Dissonances. Les Études Bergsoniennes 1. Paris: PUF, 1948.

DELEUZE, G. Proust et les signes. Paris, 1964.

LEOPOLDO e SILVA, F. Bergson e Proust: o impressionismo como obstáculo e transparência. In: BONI, Luis A. de (org.). Finitude e Transcendência. Petrópolis: Vozes, 1996.

GENETTE, G. Proust Polimpsesto. In Figuras. São Paulo: Perspectiva, 1972.

PROUST, M. Em Busca do Tempo Perdido. 10ª Ed. 7 vol. São Paulo: Globo, 1992. 
QUENEAU, Raymond, (org.). "Histoire des Littératures III". In: Encyclopédie de la Pléiade. Paris: Ed. Gallimard, 1958, p. 1252.

SPITZER, L. Etúdes de Style. Paris: Galliard, 1970.

SOUZA, S. La Philosophie de Marcel Proust. Paris: Les Editions Rieder, 1939. 